\title{
THE MINIMUM EFFICIENT SCALE: A NOTE ON TERMINOLOGY
}

\author{
Doç. Dr. Lâle DAVUT*
}

The minimum efficient scale is defined in two alternative ways in microeconomics textbooks: 1) The level of output that minimizes the long-run average cost is called the minimum efficient scale (Varian, 1990:410). According to this definition, the output level which corresponds to the minimum point of a U-shaped long-run average cost curve as well as any output level which corresponds to the horizontal part of a L-shaped or saucer-shaped long-run average cost curve can be called the minimum efficient scale. 2) The output level at which the long-run average cost curve first becomes horizontal is called the minimum efficient scale (Begg, Fischer, Dornbusch 1991:118). According to this definition, the minimum efficient scale is a concept relevant for only L-shaped or saucer-shaped long-run average cost curves ${ }^{1}$. Yet, in textbooks providing this definition the minimum efficient scale is diagrammatically illustrated using strictly U-shaped longrun average cost curves ${ }^{2}$.

Alternative definitions of the minimum efficient scale seem to refer to different points on the long-run average cost curve. This variation in the reference points gives rise to a complication since long-run average cost curves can take different shapes. Lshaped or saucer shaped long-run average cost curves reach a minimum point and then stabilize over a range of outputs such that the long-run average cost is at a minimum for more than one output level. On the other hand, a strictly U-shaped long-run average cost curve first declines, reaches a minimum point and rises immediately thereafter such that there is only one output level which corresponds to the minimum point of the curve. The

\footnotetext{
* A.Ũ. Siyasal Bilgiler Fakultesi Ögretim Uyesi.

In some of the textbooks the term "minimum efficient scale of plant" is used. It is defined as the smallest output at which long-run average cost is a minimum (Mansfield, 1994:394). This definition can be misleading because the terms "plant size" and "level of output are used interchangeably. The minimum efficient scale of output is the smallest level of output at which the long-run average cost is at a minimum. At this level of output, a short-run average total cost curve is tangent to the long-run average curve and plant size is indicated by the short-run average total cost curve.

${ }^{2}$ For example in Begg, Fischer, Dombusch (1991:158) the minimum point of a strictly Ushaped long-run average cost curve is labeled as the minimum efficient scale.
} 
term "minimum efficient scale" of production implies that there is more than one efficient scale of output and the srnallest one among them is being referred to. Viewed in this way, the term "minimum cfficient scale" of production should be used only in relation to L-shaped or saucher shaped long-run average cost curves ${ }^{3}$. When the long-run average cost curve is strictly $U$-shaped, there is a single level of output which corresponds to the minimum print of the long-run average cost curve and there is no need to describe this particular scale of output as the "minimum" one.

The mimimum point of a strictly $U$-shaped long-run average cost curve undoubtedly bears importanc: in economic analysis and there is a need to name it. Furthermore, the concepts thal are related to the minimum points of differently shaped long-run average cost curvs should reflect the basic characteristic shared by these points. I suggest that the term "the efficient scale of output" should be used to indicate the output level corresponding to the minimum point of a strictly U-shaped long-run average cost curve. Using two different yet related terms such as "the efficient scale of output" and "the minimum efficient scale" instead of a single term such as "the minimum efficient scale" would enable the economist to relate the concept of the efficient scale to the shape of the long run average cost curve. Since long-run average cost curves are U-shaped, Lshaped or saucer-shaped, a single term such as "the minimum efficient scale" will be inadequate in capturing all the imporiant features of the minimum points of differently shaped long-run average cost curves ${ }^{4}$.

The minimum efficient scale of production is a concept which is also used in making inferences about the market structure from the relative positions of the market demand curve and the long-run average cost function of the firm. The standard microeconomics textbook practice on this subject is that if the minimum efficient scale is small relative to the size of the market, competitive conditions are expected to prevail (Varian, 1990:409). A related subject in industrial economics is the efficient industry configurations and the number of firms required for such industry configurations. The minimum efficient scale of production is used in figuring out the number of firms required for efficient industry configurations. If the long-run average cost curve is saucershaped, the biggest output level at which the long-run average cost is at a minimum gains importance. Such an output level should be called "the maximum efficient scale". The maximum efficient scale of output will be used to compute the minimum number of firms required for efficient ind ustry configurations (Panzar, 1989:38).

${ }^{3} \mathrm{~A}$ good example of the definition and usage of the minimum efficient scale which emphasizes this point is in Rulfin (1992:217).

${ }^{4}$ In some of the microeconomics tekxtbooks, the terms "the efficient scale" and "the most efficient scale" are used in place of "the minimum efficient scale". The efficient scale, in this context, is defined as "the level (or levels) of production corresponding to the minimum long-run average cost." (Mas-Colell, Whinston, Green, 1995:145). The efficient scale defined as such can be used in relation to U-shaped as well as L-shaped or saucershaped long-run average cost curves. Yet, if there is a group of output levels at which the long-run average cost is constant at its minimum we still need a term to indicate the smallest on in such a group of output levels. In this case, the term "the minimum efficient scale" serves the purpose well.

The term "the most efficient scale" as used in Tirole (1990:19) is not as good as the term "the minimum efficient scalc" in conveying the message that the smallest one among the efficient scales is being referted to. 
The term "maximum efficient scale" should be used as commonly as the term "minimum efficient scale" in microeconomics. The trio of the terms; efficient, minimum efficient and maximum efficient scales will be very helpful in providing clear-cut definitions.

\section{REFERENCES}

Begg, D., Fischer, S., Dornbusch, R. (1991) Economics, (3 ${ }^{\text {rd }}$ edn.), London, McGrawHill.

Mansfield, E. (1994) Microeconomics, ( th $^{\text {th }}$ edn.), New York, W.W. Norton and Company.

Mas-Colell, A., Whinston, M.D., Green, J.R. (1995) Microeconomic Theory, New York, Oxford University Press.

Ruffin, J.R. (1992) Intermediate Microeconomics, (2 ${ }^{\text {nd }}$ edn.); Harper Collins Publishers Inc.

Tirole, J. (1990) The Theory of Industrial Organization, MIT Press.

Panzar, J.C. (1989) "Technological Determinants of Firm and Industry Structure", in The Handbook of Industrial Organization, eds. R. Schmalensee and R. Willig, North Holland, Amsterdam, Elsevier Science Publishers, 4-59.

Varian, H.R. (1990) Intermediate Microeconomics, New York, W.W. Norton and Company. 